\title{
EXISTENCE OF POSITIVE SOLUTIONS OF A CLASS OF QUASILINEAR ELLIPTIC EQUATIONS ON $\mathbb{R}^{N}$
}

\author{
JiNG Mo AND ZUODONG YANG
}

Abstract. In this paper we study the following problem: $-\Delta_{p} u+|u|^{p-2} u=k(x) f(u)+h(x)$, $x \in \mathbb{R}^{N}$, where $u \in W^{1, p}\left(\mathbb{R}^{N}\right), u>0$ in $\mathbb{R}^{N}$. Under appropriate assumptions on $k, h$ and $f$, we prove that problem has at least two positive solutions.

Mathematics subject classification (2010): 35J25, 35J67, 35J20.

Keywords and phrases: nonhomogeneous quasilinear elliptic equation, Mountain Pass Theorem, Pohozaev type identity.

\section{REFERENCES}

[1] J. Garcia-Azorero And I. Peral, Multiplicity of solutions for elliptic problems with critical exponent or with a nonsymmetric term, Trans. Amer. Math. Soc., 323, 2 (1991), 877-895.

[2] J. GARCiA-AZORERO AND I. Peral, Existence and non-uniqueness for the p-Laplacian: nonlinear eigenvalues, Comm. Partial Differential Equations, 12 (1987), 1389-1430.

[3] J.F. BONDER AND J.D. Rossi, Existence results for the p-Laplacian with nonlinear boundary condition, J. Math.Anal. Appl., 263, 1 (2001), 195-223.

[4] I. Ekeland, Convexity Methods in Hamiltonian Mechanics, Springer, 1990.

[5] Z.M. GuO, Existence and uniqueness of the positive radial solutions for a class of quasilinear elliptic equations, Appl. Anal. 47, 1 (1992), 173-190.

[6] Z.M. GUO AND Z.D. YANG, Some uniqueness results for a class of quasilinear elliptic eigenvalue problems, Acta Mathematica Sinica (new series), 14, 2 (1998), 245-260.

[7] Z.M. Guo, Some existence and multiplicity results for a class of quasilinear elliptic eigenvalue problems, Nonlinear Anal., 18 (1992), 957-971.

[8] Z.M. Guo AND J.R.L. WeBB, Uniqueness of positive solutions for quasilinear elliptic equations when a parameter is large, Proc. Royal Soc. Edinburgh, 124, A (1994), 189-198.

[9] Z.M. GuO, On the number of positive solutions for quasilinear elliptic eigenvalue problems, Nonlinear Anal., 27, 2 (1996), 229-247.

[10] D.D. HAI, Positive solutions of quasilinear boundary value problems, J. Math.Anal. Appl., 217 (1998), 672-686.

[11] L. JEAN, Two positive solutions for a class of nonhomogeneous elliptic equations, Differential Integral Equations, 10 (1997), 609-624.

[12] L. JEAn, On the existence of bounded Palais-Smale sequences and applications to a LandesmanLazer-type set on $\mathbf{R}^{N}$, Proc. Roy. Soc. Edinburgh Sect. A, 129 (1999), 787-809.

[13] Y.H. KIM, A global bifurcation for nonlinear equations with nonhomogeneous part, Nonlinear Analysis, doi:10.1016/j.na.2008.11.028.

[14] S.J. LI, S.P. WU AND H.S. ZHOU, Solutions to semilunar elliptic problems with combined nonlinearities, J. Differential Equations, 185 (2002), 200-224.

[15] Z.L. LiU AND Z.Q. WANG, Existence of a positive solution of an elliptic equation on $\mathbb{R}^{N}$, Proc. Roy. Soc. Edinburgh Sect. A, 134 (2004), 191-200.

[16] C. LIU, Z. WANG AND H.S. ZHOU, symptotically linear Schrödinger equation with potential vanishing at infinity, J. Differential Equations, 245 (2008), 201-222.

[17] C.A. StuART And H.S. ZHOU, Applying the mountain pass theorem to an asymptotically linear elliptic equation on $\mathbb{R}^{N}$, Comm. Partial Differential Equations, 24 (1999), 1731-1758. 
[18] J.B. Su, Z.Q. WANG AND M. WILLEM, Weighted Sobolev embedding with unbouded and decaying radial potentials, J.Differential Equations, 238 (2007), 201-219.

[19] Z.P. WANG AND H.S. ZHOU, Positive solutions for a nonhomogeneous elliptic equation on $\mathbb{R}^{N}$ without (AR) condition, J. Math. Anal. Appl. 353 (2009), 470-479.

[20] B.J. XUAN AND Z.C. CHEN, Solvability of singular quasilinear elliptic equation, Chinese Ann. Math., 20A, 1 (1999), 117-128.

[21] Z.D. YANG, Existence of positive entire solutions for singular and non-singular quasi-linear elliptic equation, J. Comput. Appl. Math., 197 (2006), 355-364.

[22] X.P. ZHU, A perturbation result on positive entire solutions of a semilinear elliptic equation, J. Differential Equations, 92 (1991), 163-178.

[23] X.P. ZHU AND H.S. ZHOU, Existence of multiple positive solutions of inhomogeneous semilinear elliptic problems in unbounded domains, Proc. Roy. Soc. Edinburgh Sect. A, 115 (1990), 301-318. 